\title{
Supra-Ductile and High-Strength Manganese-TRIP/TWIP Steels for High Energy Absorption Purposes
}

\author{
Georg FROMMEYER, Udo BRÜX and Peter NEUMANN \\ Max-Planck-Institut für Eisenforschung GmbH, Max-Planck-Strasse 1, 40237 Düsseldorf, Germany. E-mail: bruex@mpie.de \\ (Received on June 3, 2002; accepted in final form on October 26, 2002)
}

\begin{abstract}
The microstructural properties of advanced high strength and supra-ductile TRIP and TWIP steels with high-manganese concentrations (15 to 25 mass\%) and additions of aluminum and silicon (2 to 4 mass\%) were investigated as a function of temperature $\left(-196\right.$ to $\left.400^{\circ} \mathrm{C}\right)$ and strain rate $\left(10^{-4} \leq \dot{\varepsilon} \leq 10^{3} \mathrm{~s}^{-1}\right)$. Multiple martensitic $\gamma_{\mathrm{fcc}}$ (austenie) $\rightarrow \varepsilon_{\mathrm{hcp}}^{\mathrm{Ms}}$ (hcp-martensite) $\rightarrow \alpha_{\mathrm{bcc}}^{\mathrm{Ms}}$ (bcc-martensite)-transformations occurred in the TRIP steel when deformed at higher strain rates and ambient temperatures. This mechanism leads to a pronounced strain hardening and high tensile strength $(>1000 \mathrm{MPa})$ with improved elongations to failure of $>50 \%$. The austenitic TWIP steel reveals extensive twin formation when deformed below $150^{\circ} \mathrm{C}$ at low and high strain rates. Under these conditions extremely high tensile ductility (>80 \%) and energy absorption is achieved and no brittle fracture transition temperature occurs. The governing microstructural parameter is the stacking fault energy $\Gamma_{\mathrm{fcc}}$ of the fcc austenite and the phase stability determined by the Gibbs free energy $\Delta G^{\gamma \rightarrow \varepsilon}$. These factors are strongly influenced by the manganese content and additions of aluminum and silicon.

The stacking fault energy $\Gamma_{\mathrm{fcc}}$ and the Gibbs free energy $\mathrm{G}$ were calculated using the regular solution model. The results show that aluminum increases $\Gamma_{\mathrm{fcc}}$ and suppresses the $\gamma_{\mathrm{fcc}} \rightarrow \varepsilon_{\mathrm{hcp}}^{\mathrm{Ms}}$ transformation, whereas silicon sustains the $\gamma_{\mathrm{fcc}} \rightarrow \varepsilon_{\mathrm{hcp}}^{\mathrm{Ms}}$ transformation and decreases the stacking fault energy. At the critical value of $\Gamma_{\mathrm{fcc}} \approx 25 \mathrm{~mJ} / \mathrm{mol}$ and for $\Delta G^{\gamma \rightarrow \varepsilon}>0$, the twinning mechanism is favored. At lower stacking fault energy of $\left(\Gamma_{\mathrm{fcc}}<16 \mathrm{~mJ} / \mathrm{mol}\right.$ and for $\Delta G^{\gamma \rightarrow \varepsilon}>0$, martensitic phase transformation will be the governing deformation mechanism.
\end{abstract}

The excellent ductility and the enhanced impact properties enable complex deep drawing or stretch forming operations of sheets and the fabrication of crash absorbing frame structures.

KEY WORDS: high-strength; high alloy steel; TRIP; TWIP; ductility; cryogenic alloy; toughness; twinning; martensite.

\section{Introduction}

New design concepts for the construction of advanced light-weight and crash resistant transportation systems require the development of high strength and supra-ductile steels combined with enhanced energy absorption and reduced specific weight. Another important aspect is the improvement in deep drawing and stretch forming of sheet steels for the manufacturing of tailored blanks and stiffened components.

High-manganese steels containing 15 to 25 mass $\%$ Mn and additions of silicon and aluminum of about 2 to 4 mass \% exhibit high strength and exceptional plasticity due to extensive twin formation $\left(\gamma \rightarrow \gamma_{\mathrm{T}}^{\prime}\right)$ under mechanical load TWIP effect-Twinning Induced Plasticity — or via multiple martensitic transformations $\left(\gamma_{\mathrm{fcc}} \rightarrow \varepsilon_{\mathrm{hcp}}^{\mathrm{Ms}} \rightarrow \alpha_{\mathrm{bcc}}^{\mathrm{Ms}}\right)$ TRIP effect-Transformation Induced Plasticity-.

The TWIP mechanism occurs in stable austenite where the Gibbs free energy $\Delta G^{\gamma \rightarrow \varepsilon}$ of the martensitic reaction $\gamma_{\mathrm{fcc}} \rightarrow \varepsilon_{\mathrm{hcp}}^{\mathrm{Ms}}$ is positive of about $\Delta G^{\gamma \rightarrow \varepsilon} \approx 110$ to $250 \mathrm{~J} / \mathrm{mol}$ and the stacking fault energy $\Gamma_{\mathrm{fcc}}$ is relatively low of the order of $\Gamma_{\mathrm{fcc}} \approx 25 \mathrm{~mJ} / \mathrm{m}^{2}$. The TRIP effect reveals in metastable austenite where $\Delta G^{\gamma \rightarrow \varepsilon}$ is negative of about $\Delta G^{\gamma \rightarrow \varepsilon}=-220 \mathrm{~J} / \mathrm{mol}$ or less depending upon the composition. The stacking fault energy is rather low of the order of $\Gamma_{\text {fcc }} \lesssim 16 \mathrm{~mJ} / \mathrm{m}^{2}$, which implies preferential formation of the hexagonal close packed $\varepsilon$-phase. Generally, additions of aluminum to high manganese-iron alloys increase the stacking fault energy of the austenite and suppress the martensitic $\gamma_{\mathrm{fcc}} \rightarrow \varepsilon_{\mathrm{hcp}}^{\mathrm{Ms}}$ transformation, whereas silicon decreases the stacking fault energy and sustains the martensitic phase transformation. ${ }^{1-3)}$

The described TRIP and TWIP effects are promoting specific mechanical properties. The high-manganese TRIP steel exhibits a pronounced strain-hardening behavior with maximum stress exponents of $n=0.8$, high tensile strength of about $1100 \mathrm{MPa}$, and improved elongations to failure of $\varepsilon_{\text {tot }}=55 \%$, respectively.

The TWIP steel shows a relatively low flow stress of $R_{\mathrm{p} 0.2}=280 \mathrm{MPa}$ and a moderate tensile strength of $650 \mathrm{MPa}$. The extremely high elongation to failure of $\varepsilon_{\mathrm{f}}=95 \%$, and the specific energy absorption is more than two times of that of conventional high strength deep-drawing steels. The impact toughness is on a high level and independent upon 
the test temperature within a wide temperature range from -196 to $400^{\circ} \mathrm{C}$ and beyond.

The tensile properties of the newly developed high-manganese TRIP/TWIP steels of the basic compositions: Fe$15 \mathrm{Mn}-3 \mathrm{Al}-3 \mathrm{Si}$ mass\% (TRIP steel) and $\mathrm{Fe}-25 \mathrm{Mn}-3 \mathrm{Al}-$ $3 \mathrm{Si}$ mass $\%$ (TWIP steel) and one in between of the composition $\mathrm{Fe}-20 \mathrm{Mn}-3 \mathrm{Al}-3 \mathrm{Si}$ mass\% which reveals TRIP and TWIP behavior were investigated as a function of the temperature and strain rate. The impact toughness and specific energy absorption under dynamic loading at very high strain rates up to $\dot{\varepsilon}=10^{3} \mathrm{~s}^{-1}$ were evaluated.

The influence of the deformation rate on the deep drawing and stretch forming behavior of the TRIP steel was studied in greater detail by performing cupping tests and digitalized stress-strain analysis.

The temperature and strain rate dependent mechanical properties of the TRIP and TWIP steels are described and discussed with regard to microstructural changes induced either by extensive twinning or by multiple martensitic phase transformations.

\section{Experimental Procedure}

The TRIP and TWIP steels under investigation were prepared by induction melting in an argon atmosphere and cast to round bars of $24 \mathrm{~mm}$ in diameter. The samples were swaged to $77 \%$ reduction in area, austenite annealed at $1000^{\circ} \mathrm{C}$ for $2 \mathrm{~h}$ and subsequently water quenched. Tensile tests were performed in the temperature regime from -196 to $400^{\circ} \mathrm{C}$ at the strain rate of $10^{-4} \mathrm{~s}^{-1}$. In addition tensile test were carried out in the strain rate range between $10^{-3} \leq \dot{\varepsilon} \leq 10^{3} \mathrm{~s}^{-1}$ specifically for the TWIP steel. For performing high strain rate tests at $10^{2} \leq \dot{\varepsilon} \leq 10^{3} \mathrm{~s}^{-1}$ a flywheel testing facility and a split Hopkinson bar measuring device were used. ${ }^{4,5)}$ The temperature dependent impact toughness was determined by performing charpy impact tests. Hot and cold rolled sheets with a reduction in area of $66 \%$ of the $\mathrm{Fe}-15 \mathrm{Mn}-3 \mathrm{Al}-3 \mathrm{Si}$ mass$\%$ TRIP steel with varying dimensions were deformed in Erichsen cupping tests at different strain rates. The local biaxial deformation states of the samples were digitally determined by a vision-based surface strain and surface geometry measurement system. The forming limit curves are presented by the local principal strains $\varphi_{1}$ (major) and $\varphi_{2}$ (minor) of every specimen in order to quantify the local plastic anisotropy and the deformation mode. The coexisting phases present in the microstructure were determined by X-ray diffraction. Microstructural investigations were carried out by optical microscopy, scanning electron microscopy (SEM) and transmission electron microscopy (TEM). The chemical composition and the constituent phases prior to and after tensile testing are presented in Table $\mathbf{1 .}$

\section{Results and Discussion}

\subsection{General Mechanical Properties and Related Phases of Fe-Mn-Si-Al Steels}

The high-manganese TRIP and TWIP steels exhibit different strain hardening behaviors.

The true stress $\varphi_{\text {true }} v s$. true plastic strain $\varphi$ curves are presented in Fig. 1. At low strain values of $\varphi<0.15$, the se-
Table 1. Chemical composition of the investigated TRIP/ TWIP steels and the constituent phases prior to and after tensile testing at room temperature; strain rate $\dot{\varepsilon}=10^{-4} \mathrm{~s}^{-1}$

\begin{tabular}{l|c|c|c|c|c|c|c|c}
\hline & $\begin{array}{c}\text { Mn } \\
{[w 1 \%]}\end{array}$ & $\begin{array}{c}\text { Si } \\
{[\mathbf{w} \%]}\end{array}$ & $\begin{array}{c}\text { Al } \\
{[w+\%]}\end{array}$ & $\begin{array}{c}\mathbf{C} \\
\mathbf{p p m}\end{array}$ & $\begin{array}{c}\mathbf{N} \\
\mathbf{p p m}\end{array}$ & $\mathbf{F e}$ & $\begin{array}{c}\text { constituent } \\
\text { prior to } \\
\text { tensite testing }\end{array}$ & $\begin{array}{c}\text { phases } \\
\text { after } \\
\text { deformation }\end{array}$ \\
\hline $\begin{array}{l}\text { Fe-15Mn-3Si-3AI } \\
\text { (TRIP-steel) }\end{array}$ & 15.8 & 3.0 & 2.9 & 200 & $<30$ & bal. & $\gamma_{\mathrm{fcc}}+\alpha_{\mathrm{bcc}}^{\text {ferr }}+\varepsilon_{\mathrm{hcp}}^{\mathrm{Ms}}$ & $\gamma_{\mathrm{fcc}}+\alpha_{\mathrm{bcc}}^{\mathrm{ferr}}+\alpha_{\mathrm{bcc}}^{\mathrm{Ms}}$ \\
\hline $\begin{array}{l}\text { Fe-20Mn-3Si-3AI } \\
\text { (TRIP/TWIP-steel) }\end{array}$ & 20.1 & 2.8 & 2.9 & 400 & $<30$ & bal. & $\gamma_{\mathrm{fcc}}+\varepsilon_{\mathrm{hcp}}^{\mathrm{Ms}}$ & $\gamma_{\mathrm{fcc}}+\varepsilon_{\mathrm{hcp}}^{\mathrm{Ms}}+\alpha_{\mathrm{bcc}}^{\mathrm{Ms}}$ \\
\hline $\begin{array}{l}\text { Fe-25Mn-3Si-3AI } \\
\text { (TWIP-steel) }\end{array}$ & 25.6 & 3.0 & 2.8 & 300 & $<30$ & bal. & $\gamma_{\mathrm{fcc}}$ & $\gamma_{\mathrm{fcc}}$ \\
\hline
\end{tabular}

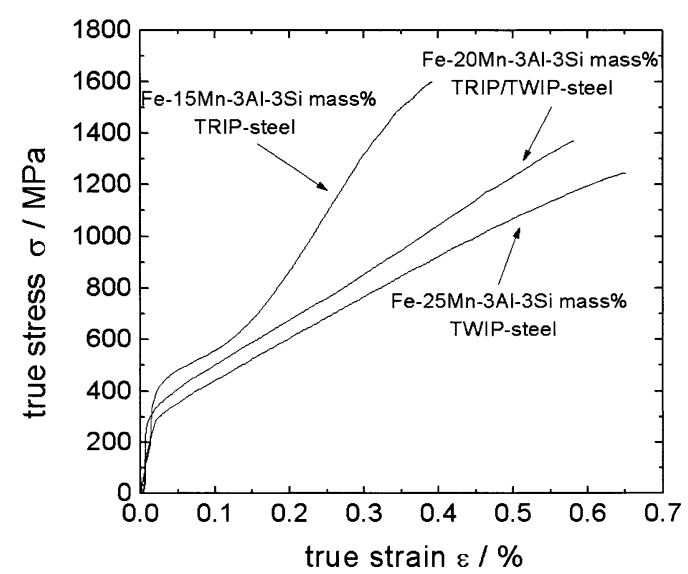

Fig. 1. True stress vs. true plastic strain curves of the TRIP and TWIP steels; test temperature: $20^{\circ} \mathrm{C}$, strain rate: $\dot{\varepsilon}=$ $10^{-4} \mathrm{~s}^{-1}$.

lected steels show moderate strain hardening behavior (strain hardening exponent $n \leq 0.4$ ).

At higher strains of $\varphi>0.15$ the steels with 15 mass $\%$ $\mathrm{Mn}$ and 20 mass $\%$ Mn reveal a change in the curvatures of their stress-strain curves due to the formation of stressinduced $\alpha_{\mathrm{bcc}}^{\mathrm{Ms}}$-martensite resulting in a strong increase in the work hardening rate and a high stress exponent. This unique feature of the stress-strain curve is typical for TRIP steels. ${ }^{6-10)}$ In contrast the steel with 25 mass $\%$ Mn and additions of 3 mass $\% \mathrm{Al} / \mathrm{Si}$ does not show any change in the curvature of the stress-strain curve. X-ray diffraction analysis revealed that neither $\alpha_{\mathrm{bcc}}^{\mathrm{Ms}}$-nor $\varepsilon_{\mathrm{hcp}}^{\mathrm{Ms}}$-martensite was formed. Optical and scanning electron microscopy showed a high density of deformation twins in the deformed tensile specimen. The TWIP steel experienced enhanced plasticity by stress-induced twin formation. The steel containing 20 mass $\% \mathrm{Mn}$ and 3 mass \% Al/Si exhibits simultaneous TRIP and TWIP behavior due to its low stacking fault energy and the metastable austenite. The relatively high strain-hardening rate is not so pronounced as that of the genuine TRIPsteel, where the strain-hardening rate amounts to $d \sigma_{\text {true }} /$ $d \varphi_{\text {true }}>4000$, respectively.

The extent of the stress induced martensitic transformation in the TRIP and TWIP steels during deformation is illustrated in Fig. 2, in which the volume fractions of the coexisting phases in the undeformed state and after strain to failure are displayed. The initial microstructure of the $\mathrm{Fe}-15 \mathrm{Mn}-3 \mathrm{Al}-3 \mathrm{Si}$ mass\% TRIP steel, consisting of ferrite, austenite, and $\varepsilon$-martensite is transformed into $\alpha$-marten- 

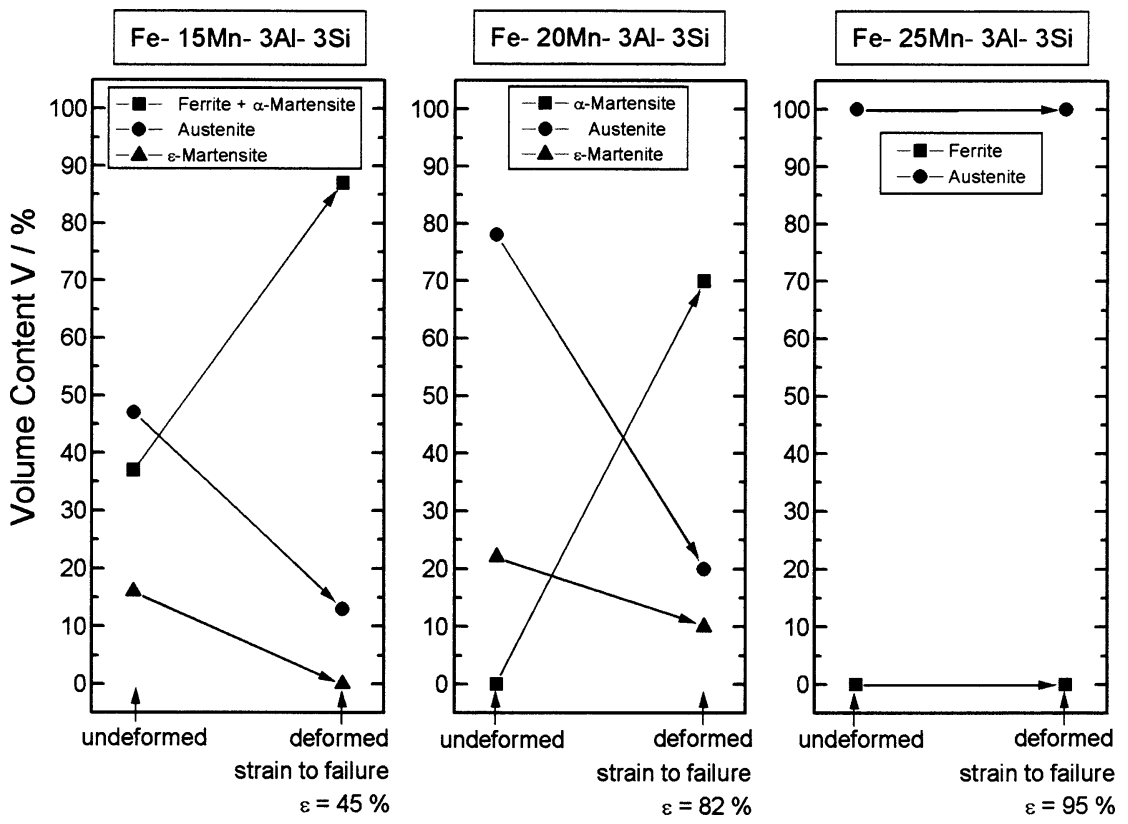

Fig. 2. Volume fractions of the coexisting phases: $\alpha_{\mathrm{bcc}}^{\text {ferrite }} / \alpha_{\mathrm{bcc}}^{\mathrm{Ms}}, \gamma_{\mathrm{fcc}}^{\text {aust }}$, and $\varepsilon_{\mathrm{hcp}}^{\mathrm{Ms}}$ of the $\mathrm{Fe}-15 \mathrm{Mn}-3 \mathrm{Al}-3 \mathrm{Si}$ mass $\%$ TRIP steel, Fe-20Mn-3Al-3Si mass\% TRIP/TWIP steel and Fe-25Mn-3Al-3Si mass\% TWIP steel. The volume fractions of these steels are displayed in the undeformed state and after strain to failure.

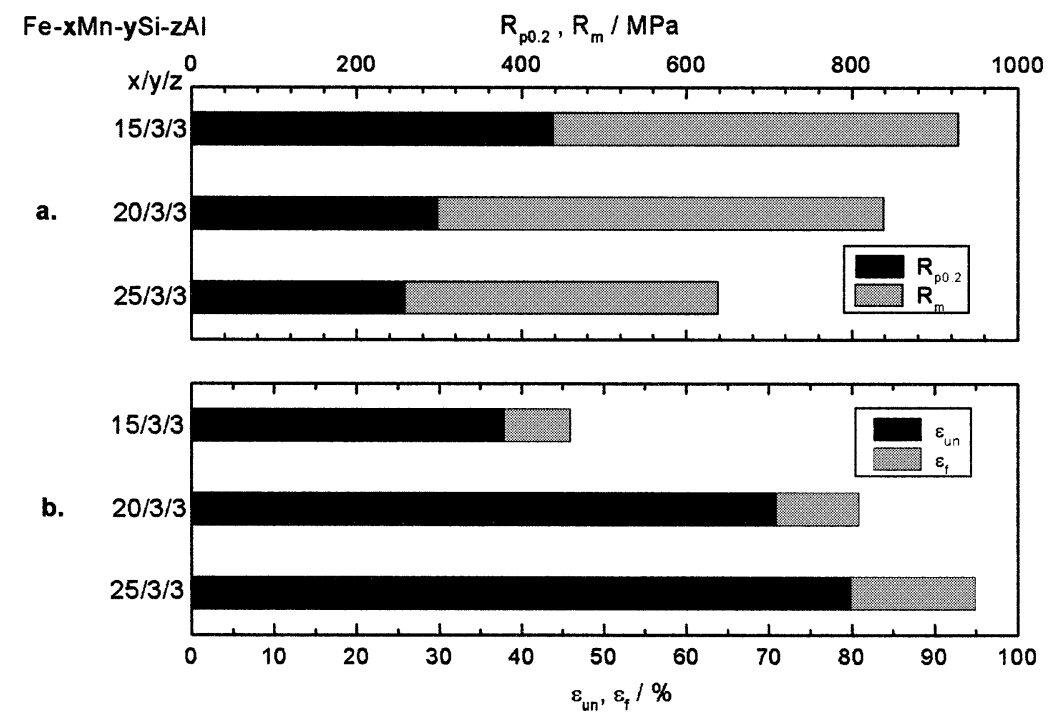

Fig. 3. Bar diagram representing the mechanical properties of TRIP and TWIP steels. a: Yield stress $R_{\mathrm{p} 0.2}$ (black marked bars) and ultimate tensile strength $R_{\mathrm{m}}$ (gray marked bars), b: Uniform $\varepsilon_{\mathrm{un}}$ (black marked bars) and total elongations $\varepsilon_{\mathrm{f}}$ (gray marked bars). Test temperature: $20^{\circ} \mathrm{C}$, strain rate: $\dot{\varepsilon}=10^{-4} \mathrm{~s}^{-1}$.

site and retained ferrite and austenite due to the TRIP effect. Likewise, the TRIP effect occurs in the Fe-20Mn3Al-3Si mass\% TRIP/TWIP steel, identified by the martensitic transformation in the deformed state. Simultaneously, extensive twin formation is taking place, which is revealed by transmission electron microscopy. Effected by the simultaneous twin formation the strain-hardening rate is lower compared to the Fe-15Mn-3Al-3Si mass\% TRIP steel (see Fig. 1). In contrast the $\mathrm{Fe}-25 \mathrm{Mn}-3 \mathrm{Al}-3 \mathrm{Si}$ mass $\%$ TWIP steel does not show any stress induced martensitic transformation. The microstructure remains completely austenitic during the entire deformation process (Fig. 2). The extraordinary strain to failure of $95 \%$ is exclusively effectuated by intensive twin formation.

The tensile properties of the selected TRIP and TWIP steels are illustrated in the bar diagram of Figs. 3(a)-3(b). Figure 3(a) shows that the yield strength $R_{\mathrm{p} 0.2}$ and the ultimate tensile strength $R_{\mathrm{m}}$ are decreasing from about 930 to $640 \mathrm{MPa}$ with increasing Mn content due to the stabilization of austenite and the diminishing volume fractions of the coexisting $\alpha$-ferrite and $\varepsilon_{\mathrm{hcp}}^{\mathrm{Ms}}$-martensite phases. Figure 3(b) displays the total elongations $\varepsilon_{\mathrm{f}}$, which are increasing from 46 to $95 \%$ at high manganese content of about 25 mass $\%$ Mn. It should be mentioned that at Mn contents higher than 25 mass\% $\mathrm{Mn}$ the total elongation is nearly constant or slightly lower. ${ }^{11)}$ The phases present in the steels before and after tensile testing are listed in Table 1. With increasing Mn content the amount of $\alpha_{\mathrm{bcc}}{ }^{-}$and $\varepsilon_{\mathrm{hcp}}$-phase will be suppressed. The multiphase TRIP and TRIP/TWIP steels with the constituent phases: 
$\gamma_{\mathrm{fcc}}+\alpha_{\mathrm{bcc}}+\varepsilon_{\mathrm{hcp}}$ and $\gamma_{\mathrm{fcc}}+\varepsilon_{\mathrm{hcp}}$ experienced the martensitic $\gamma_{\mathrm{fcc}} \rightarrow \varepsilon_{\mathrm{hcp}}^{\mathrm{Ms}}$ and $\varepsilon_{\mathrm{hcp}}^{\mathrm{Ms}} \rightarrow \alpha_{\mathrm{bcc}}^{\mathrm{Ms}}$ transformations. ${ }^{12,13)}$

\subsection{Temperature Dependent Mechanical Properties of the TRIP Steel}

Figure 4(a) shows the variation of the tensile stresses $R_{\mathrm{p} 0.2}$ and $R_{\mathrm{m}}$ and elongations $\varepsilon_{\mathrm{un}}$ and $\varepsilon_{\mathrm{f}}$ as functions of the temperature of the $\mathrm{Fe}-15 \mathrm{Mn}-3 \mathrm{Al}-3 \mathrm{Si}$ mass\% TRIP steel. The diagram is subdivided into 3 regimes. In the temperature regime $\mathrm{I}$ between $150^{\circ} \mathrm{C} \leqslant T \leqslant 400^{\circ} \mathrm{C}$ where the stress and elongation values are slightly increasing no stress induced phase transformations were detected by X-ray diffraction. The governing deformation mode is crystallographic slip via dislocation glide in the in $\gamma_{\mathrm{fcc}}$-austenite matrix

In the temperature regime II from $80^{\circ} \mathrm{C} \leqslant T \leqq 150^{\circ} \mathrm{C}$ stress induced martensitic $\gamma_{\mathrm{fcc}} \rightarrow \varepsilon_{\mathrm{hcp}}^{\mathrm{Ms}} \rightarrow \alpha_{\mathrm{bcc}}^{\mathrm{Ms}}$ phase transformation was detected by $\mathrm{X}$-ray diffraction and microscopy. This mechanism results in relatively high total elongations of about $60 \%$ and in a strong increase of the ultimate tensile strength from about 600 to $900 \mathrm{MPa}$, respectively. Enhanced uniform elongations occur via retardation of local necking. ${ }^{14,15)}$ Stress induced martensitic phase transformation in the $\gamma$ matrix will preferentially take place in locally formed neckings. This is due to intensive strain hardening occurring in these areas. The deformation proceeds alternatively in neighboring areas of the tensile samples, which possess lower hardening and yield stresses. This multiple deformation mechanism results in high uniform elongations. At temperatures below $80^{\circ} \mathrm{C}$ (region III) the elongations $\varepsilon_{\mathrm{f}}$ and $\varepsilon_{\mathrm{u}}$ are decreasing with decreasing temperature in spite of the martensitic phase transformation where the volume function of the $\alpha_{\mathrm{bcc}}^{\mathrm{Ms}}$-martensite is dominant, as shown in Fig. 4(b). This behavior is due to the fact that the transformation rate increases with decreasing temperature. ${ }^{16)}$ As a consequence, the martensitic transformation is completed in the early stage of deformation characterized by lower strain values and higher ultimate tensile strength up to $1250 \mathrm{MPa}$ at $-100^{\circ} \mathrm{C}$.

The volume fraction of the coexisting phases: $\alpha_{\mathrm{bcc}}^{\text {ferr }} / \alpha_{\mathrm{bcc}}^{\mathrm{Ms}}$, $\gamma_{\mathrm{fcc}}^{\text {aust }}$, and $\varepsilon_{\mathrm{hcp}}^{\mathrm{Ms}}$ of the TRIP steel as a function of the applied tensile strain is presented in Fig. 5.

The chosen test temperature is $T=20^{\circ} \mathrm{C}$, and the strain rate is $\dot{\varepsilon}=10^{-4} \mathrm{~s}^{-1}$. With increasing uniaxal deformation the amounts of austenite and $\varepsilon$-martensite are decreasing due to the martensitic transformation $\gamma_{\mathrm{fcc}}^{\text {aust }} \rightarrow \varepsilon_{\mathrm{hcp}}^{\mathrm{Ms}} \rightarrow \alpha_{\mathrm{bcc}}^{\mathrm{Ms}}$. This reaction leads to a steep slope of the total volume fraction of $V_{\alpha \text {-ferrite }}+V_{\alpha_{\mathrm{bcc}}^{\mathrm{Ms}}}$ up to a strain value of $\varepsilon \approx 30 \%$. At this degree of deformation, the volume fraction $V_{\varepsilon_{\text {hcp }}^{\text {Ms }}}$ of the hexagonal $\varepsilon$-martensite tends to zero and $V_{\gamma_{\text {fco }}} \approx 0.15$. At higher degree of deformation, the amounts of $V_{\alpha \text {-ferrite }} / \alpha_{\mathrm{bcc}}^{\mathrm{Ms}}$ and $V_{\gamma_{\mathrm{fcc}}}$ are constant. This fact implies that no proceeding stress induced martensitic transformation $\left(\gamma_{\mathrm{fcc}} \rightarrow \alpha_{\mathrm{bcc}}^{\mathrm{Ms}}\right)$ takes place due to a high level of an internal back stress state in the sample. The martensitic $\varepsilon_{\mathrm{hcp}}^{\mathrm{Ms}} \rightarrow \alpha_{\mathrm{bcc}}^{\mathrm{Ms}}$ transformation at a given strain of $\varepsilon=10 \%$ is illustrated by the optical micrographs (polarized light) in Figs. 6(a) and 6(b). The longitudinally arranged primary ferrite (bright) and retained austenite (darker) phases remain unchanged, whereas the $\alpha_{\mathrm{bcc}}^{\mathrm{Ms}}$-martensite appears in blue color and the $\varepsilon_{\mathrm{hcp}}^{\mathrm{Ms}}$-martensite shows a bright appearance.
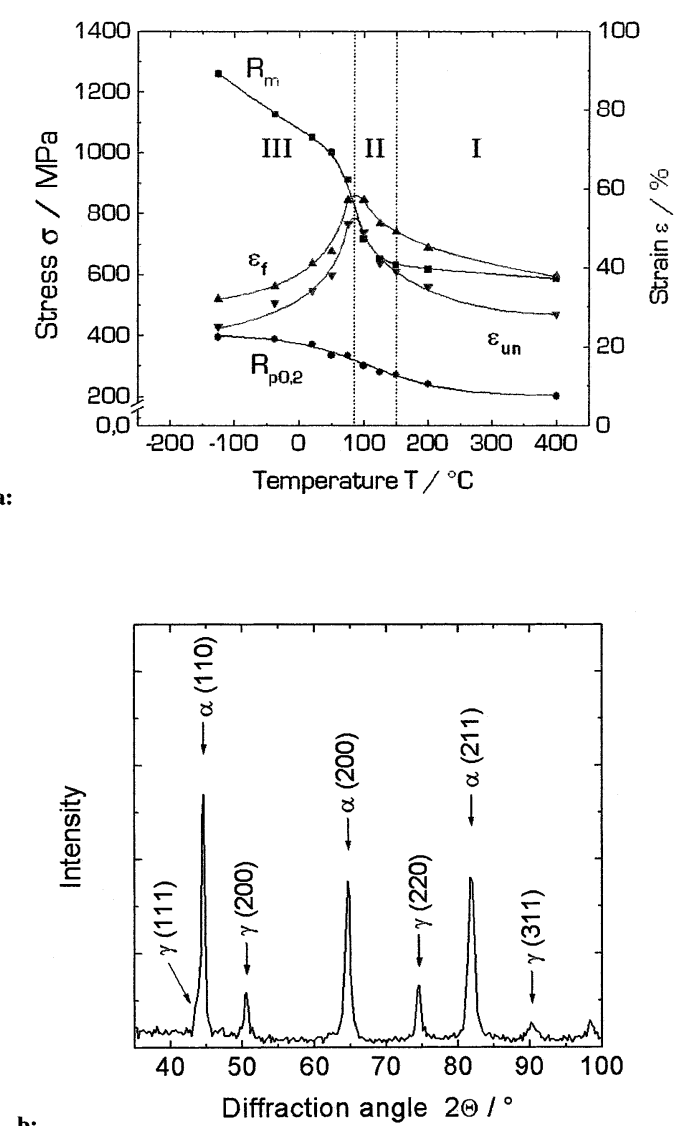

Fig. 4. Tensile properties of the $\mathrm{Fe}-15 \mathrm{Mn}-3 \mathrm{Al}-3 \mathrm{Si}$ mass\% TRIP steel as a function of the test temperature (a) and characteristic X-ray diffraction pattern (b) of a tensile sample deformed at $75^{\circ} \mathrm{C}$ (regime III); strain rate $\dot{\varepsilon}=10^{-4} \mathrm{~s}^{-1}$.

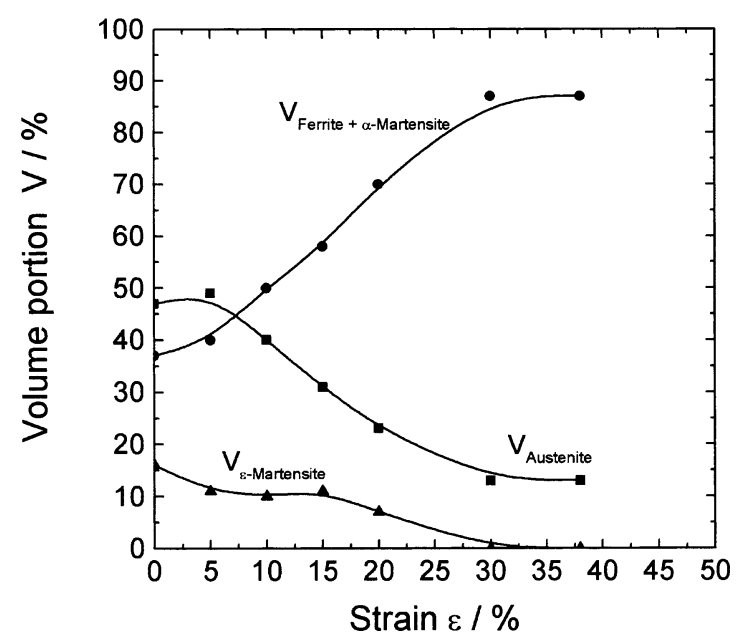

Fig. 5. Volume fractions of the coexisting phases: $\alpha_{\mathrm{bcc}}^{\mathrm{ferrite}} / \alpha_{\mathrm{bcc}}^{\mathrm{Ms}}$, $\gamma_{\mathrm{fcc}}^{\text {aust }}$, and $\varepsilon_{\mathrm{hcp}}^{\mathrm{Ms}}$ of the Fe-15Mn-3Al-3Si mass $\%$ TRIP steel as functions of the tensile strain; test temperature: $20^{\circ} \mathrm{C}$.

The martensitic phase transformation during deformation leads to extensive strain hardening so that the strain-hardening exponent is strongly increasing $(0.4<n<0.9)$ at higher true strain and ambient temperatures. Figure 7 shows the nvalue as a function of the true strain for three different temperatures. At $T=200^{\circ} \mathrm{C}$ (region I) the $n$-value is constant and below $150^{\circ} \mathrm{C}$ the $n$-value increases with increasing strain indicating the strong strain-hardening effect due to 
a:

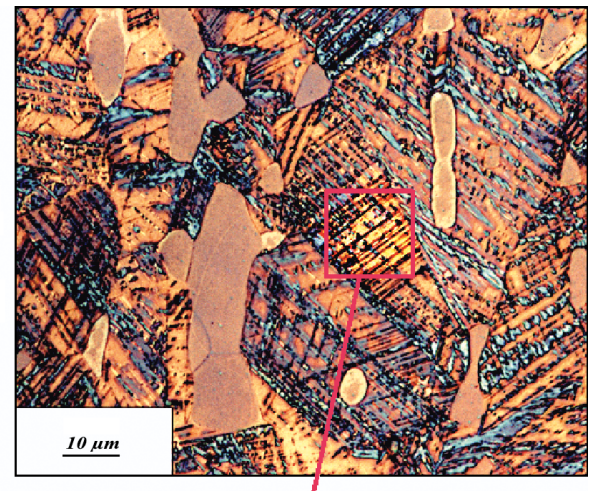

b:

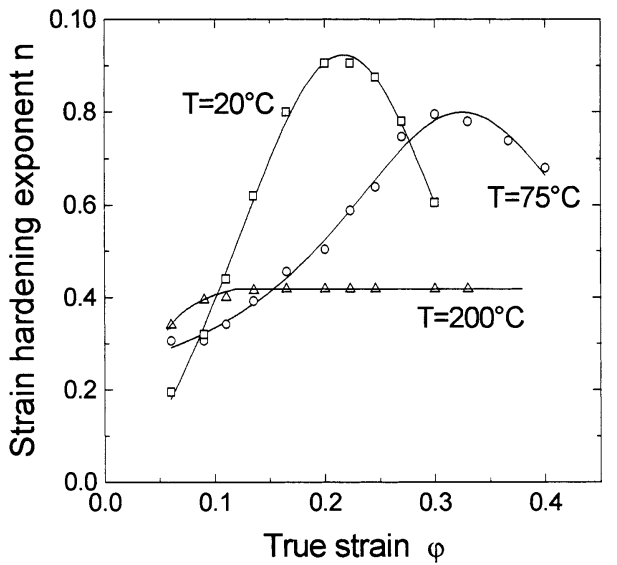

Fig. 6. Optical micrographs (polarizing light, Schumann etching) of the $\mathrm{Fe}-15 \mathrm{Mn}-3 \mathrm{Al}-3 \mathrm{Si}$ mass\% TRIP steel sample, deformed with $\varepsilon=10 \%$, strain rate $\dot{\varepsilon}=1 \times 10^{-4} \mathrm{~s}^{-1}$, magnification M: $1000 \times$.

Fig. 7. Strain hardening exponent ' $n$ ' $v s$. true strain ' $\varphi$ ' of the Fe-15Mn-3Al-3Si mass\% TRIP steel.

major true strain $\varphi_{1}$

0.4500
$0.4154-$
$0.3808-$
$0.3462-$
$0.3115-$
$0.2769-$
$0.2423-$
$0.2077-$
$0.1731-$
$0.1385-$
$0.1038-$
$0.0692-$
$0.0346-$
0.0000
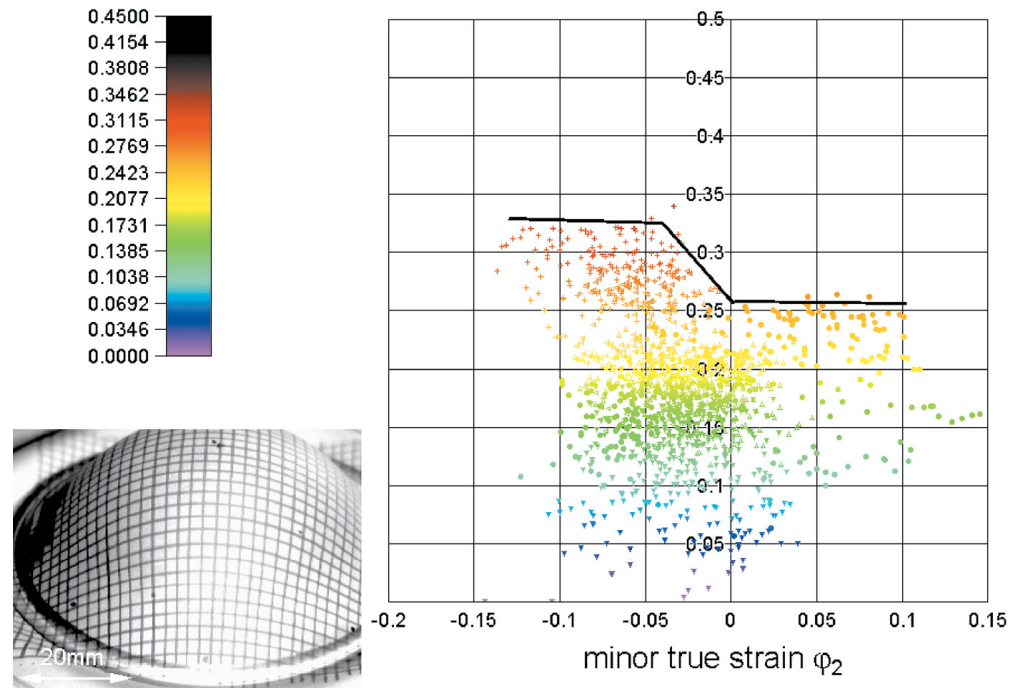

major true strain $\varphi_{1}$

0.4500
$0.4154-$
0.3808
$0.3462-$
0.3115
$0.2769-$
$0.2423-$
$0.2077-$
$0.1731-$
0.1385
0.1038
$0.0692-$
0.0346
0.0000
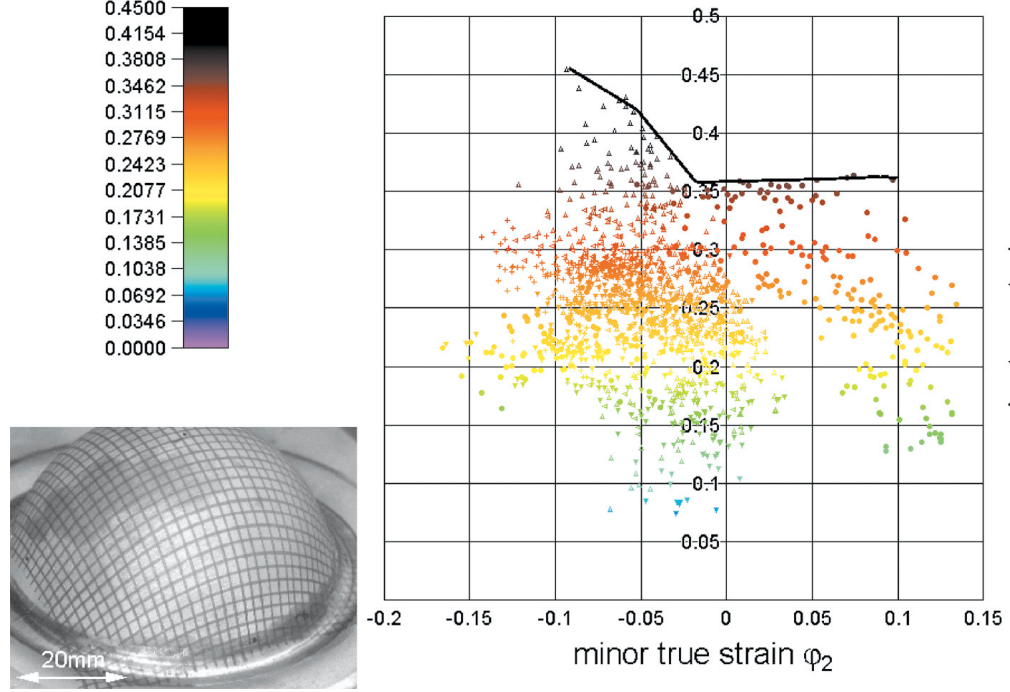

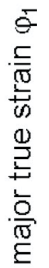

Fig. 8. Illustrates the forming limit diagram and the related forming limit curve of the $\mathrm{Fe}-15 \mathrm{Mn}-$ $3 \mathrm{Al}-3 \mathrm{Si}$ mass $\%$ TRIP steel; maximum deformation rate $\dot{\varepsilon}=2 \times 10^{-3} \mathrm{~s}^{-1}$.
Fig. 9. Illustrates the forming limit diagram with the related forming limit curve of the $\mathrm{Fe}-15 \mathrm{Mn}-$ 3Al-3Si mass\% TRIP steel recorded at the maximum deformation rate of $\dot{\varepsilon}=1 \times 10^{-1} \mathrm{~s}^{-1}$. 
the martensitic phase transformation. At $T=75^{\circ} \mathrm{C}$ the $n$ value increases with increasing true strain up to $\varphi_{\text {true }}=0.36$. This fact indicates continuous martensitic transformation. Moreover, with decreasing temperature the $n$-value exhibits an increasing slope due to the higher martensite formation rate of the proceeding phase transformation. This reaction results in a preliminary saturation of the $\alpha_{\mathrm{bcc}}^{\mathrm{Ms}}-$ martensite with decreasing elongations, and an increase in ultimate tensile strength. The discussed results show that continuous martensitic phase transformation is necessary to achieve enhanced tensile elongations via the TRIP effect.

The strain hardening and plasticity of TRIP steels can be modified by multi axial deformation, such as combined tension and torsion modes at different deformation rates. Biaxial deformation and variations in the deformation path were achieved by applying bulge tests on TRIP Steel sheets samples of different geometries. The tests were particularly carried out in order to achieve optimum deformability in deep-drawing or stretch-forming operations. Different biaxial deformation states were generated in sheet samples with various geometries. For a quantitative investigation the sheet samples were covered by grids, which enable to analyze the local biaxial deformation states.

With the aid of a digital analysis the local biaxial deformation of every grid segment is characterized by the two orthogonal strains $\varphi_{1}$ (major true strain) and $\varphi_{2}$ (minor true strain). The recorded strain values were plotted into the $\varphi_{1}-$ $\varphi_{2}$-diagram (forming limit diagram, FLD) and represent the forming limit curve (FLC).

Figure 8 displays the FLD of selected TRIP steel samples and the related forming limit curve respectively. Each coordinate $\left(\varphi_{1}, \varphi_{2}\right)$ describes the deformation state of an analyzed grid segment (see inserted picture of a deformed sheet surface). The maximum deformation rate of $\dot{\varepsilon}=2 \times$ $10^{-3} \mathrm{~s}^{-1}$ is achieved in deformation regimes where the major true strain is $\varphi_{1}>0.25$ and the minor true strain is negative.

In the deep drawing regime $\left(+\varphi_{1},-\varphi_{2}\right)$ the maximum major true strain $\varphi_{1}$ is about 0.32 . In the plain strain mode $\left(\varphi_{2}=0\right)$ the $\varphi_{1}$ value decreases to about 0.26 and remains nearly constant at the stretch-forming region, where $\varphi_{1}$ and $\varphi_{2}$ are positive.

With increasing deformation rate up to $\dot{\varepsilon}=10^{-1} \mathrm{~s}^{-1}$ the forming limit curve is shifted towards higher major true strain values (Fig. 9). The maximum major true strain is of $\varphi_{1}=0.36$ in the plain strain and stretch forming region, respectively. With decreasing minor true strain $\varphi_{2}$ in the deep drawing region $\left(+\varphi_{1},-\varphi_{2}\right)$ the major true strain increases to $\varphi_{1} \approx 0.45$ at the minor strain rate of $\varphi_{2} \approx-0.1$. The enhancement in formability of about $\varphi=0.1$ (engineering strain $\varphi \approx 10 \%$ ) with increasing deformation rates is caused by the decreasing of martensitic transformation reaction at elevated test temperatures. Due to the almost adiabatic deformation at a higher strain rate of $\dot{\varepsilon}=10^{-1} \mathrm{~s}^{-1}$ the deformed TRIP steel sheets were heated up to about $70^{\circ} \mathrm{C}$. At this temperature the transformation of stress induced $\alpha_{\mathrm{bcc}}^{\mathrm{Ms}}$ martensite takes place continuously during the entire deformation process.

At the sheet sample temperature of $70^{\circ} \mathrm{C}$, the martensitic phase transformation is retarded, compared to tension or bulge tests carried out at lower deformation rates of

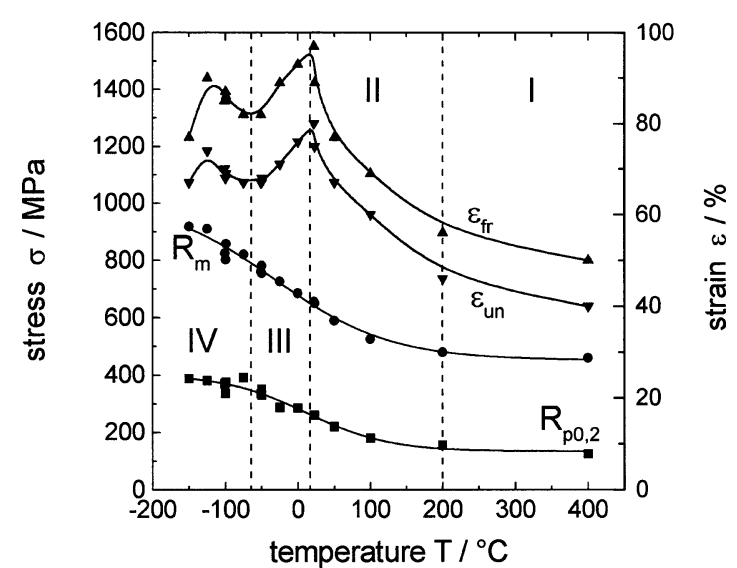

Fig. 10. Fe-55Mn-3Al-3Si mass $\%$ TWIP-steel: Yield stress $R_{\mathrm{p} 0.2}$, tensile strength $R_{\mathrm{m}}$, uniform elongation $\varepsilon_{\text {un }}$ and total elongation $\varepsilon_{\mathrm{f}}$ as functions of test temperature.

$\dot{\varepsilon}=2 \times 10^{-3} \mathrm{~s}^{-1}$ at room temperature, where the transformation is completed at lower deformation degrees. The increase in the formability is in accordance with the achieved total elongations of quasi-static uniaxial tensile tests at elevated temperatures of $80^{\circ} \mathrm{C}$ where the TRIP steel exhibits a maximum elongation of about $60 \%$, respectively.

\subsection{Temperature and Strain Rate Dependent Mechan- ical Properties of the TWIP Steel}

The stress strain behavior as a function of the deformation temperature of the TWIP steel is different from that of the TRIP steel. As shown in Fig. 10, the yield stress and the ultimate tensile strength of the austenitic TWIP steel are increasing moderately with decreasing temperature without significant hardening rate. Generally this behavior is characteristic for pure fcc metals and alloys. The amount of total elongation is $50 \%$ at $400^{\circ} \mathrm{C}$, increases to a maximum value of about $95 \%$ at room temperature and decreases again at lower temperatures. At very low temperature of $-150^{\circ} \mathrm{C}$, an elongation to failure of about $75 \%$ was recorded and at the temperature of liquid nitrogen $\left(-196^{\circ} \mathrm{C}\right)$ the total tensile elongation amounts to $65 \%$. The maximum uniform elongation is also quite high and reaches about $\varepsilon_{\text {un }}=80 \%$ at room temperature.

The undeformed tensile samples possess a fully austenitic structure with some annealing twins within the $\gamma$ austenite. This is confirmed by X-ray diffraction measurements. The stress and strain $v s$. temperature diagram is subdivided into 4 regimes. In the temperature regime I between $200^{\circ} \mathrm{C} \lesssim T \leqq 400^{\circ} \mathrm{C}$, no deformation induced martensitic phase transformation or twinning were detected by X-ray diffraction studies or SEM investigations, as shown in Figs. 11(a) and 11(b).

The main deformation mechanism in this temperature interval is dislocation glide. X-ray diffraction performed on strained tensile samples in the temperature regime II between $20^{\circ} \mathrm{C} \leqslant T \leqslant 200^{\circ} \mathrm{C}$ revealed that no phase transformation occurred. Scanning electron microscopy shows that an increasing amount of deformation twins was generated with decreasing deformation temperature, as illustrated in Figs. 12(a) and 12(b).

The extremely high elongations of more than $90 \%$ occurring at room temperature are attributed to extensive twin 

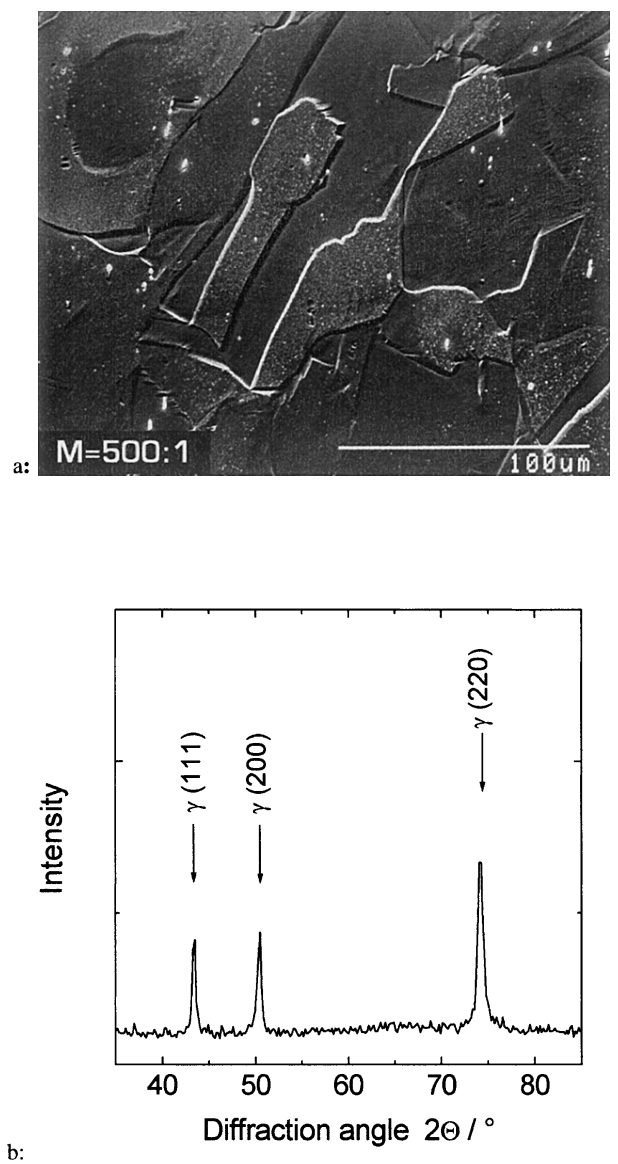

Fig. 11. SEM micrograph (a) and X-ray diffraction pattern (b) of the deformed $\mathrm{Fe}-25 \mathrm{Mn}-3 \mathrm{Al}-3 \mathrm{Si}$ mass\% TWIP-steel; test temperature: $400^{\circ} \mathrm{C}$, strain rate: $1 \times 10^{-4} \mathrm{~s}^{-1}$.

formation, as illustrated in the SEM micrograph of Fig. 12(a). The explanation for achieving enhanced elongations via the TWIP effect is principally the same as that of the TRIP effect. Stress-induced deformation twins will be preferentially formed in a local deformation region. The twin boundaries on $\{111\}$ twin planes are acting as strong barriers to subsequent dislocation motion. At deformation temperatures below $20^{\circ} \mathrm{C}$ (region III), the uniform and total elongations are decreasing with lowering the temperature to about $-70^{\circ} \mathrm{C}$. However, at even lower deformation temperatures of $-100^{\circ} \mathrm{C}$ and below (regime IV), the stacking fault energy and the stability of the austenite are decreasing and martensitic $\gamma \rightarrow \varepsilon_{\mathrm{hcp}}^{\mathrm{Ms}} \rightarrow \alpha_{\mathrm{bcc}}^{\mathrm{Ms}}$ transformation occurs as competing mechanism to twin formation, as shown in the X-ray diffraction patterns of Figs. 12(b) and 12(c). ${ }^{18)}$

The change in the yield stress, tensile strength, uniform and total elongation of the TWIP steel as a function of strain rate is illustrated in Fig. 13.

With increasing strain rate the yield stress increases over the whole strain rate range from $10^{-4}$ to $10^{3} \mathrm{~s}^{-1}$ whereas the ultimate tensile strength remains constant up to about $\dot{\varepsilon}=$ $10^{0} \mathrm{~s}^{-1}$. At strain rates beyond $10^{0} \mathrm{~s}^{-1}$ the ultimate tensile strength is increasing. The uniform and total elongations decrease with increasing strain rate up to about $10^{-1} \mathrm{~s}^{-1}$. After passing the minimum the uniform elongation increases slightly. The total elongation reaches the maximum value of about $80 \%$ and the tensile strength amounts to $800 \mathrm{MPa}$ at the extremely high strain rate of $1.5 \times 10^{3} \mathrm{~s}^{-1}$. No marten-
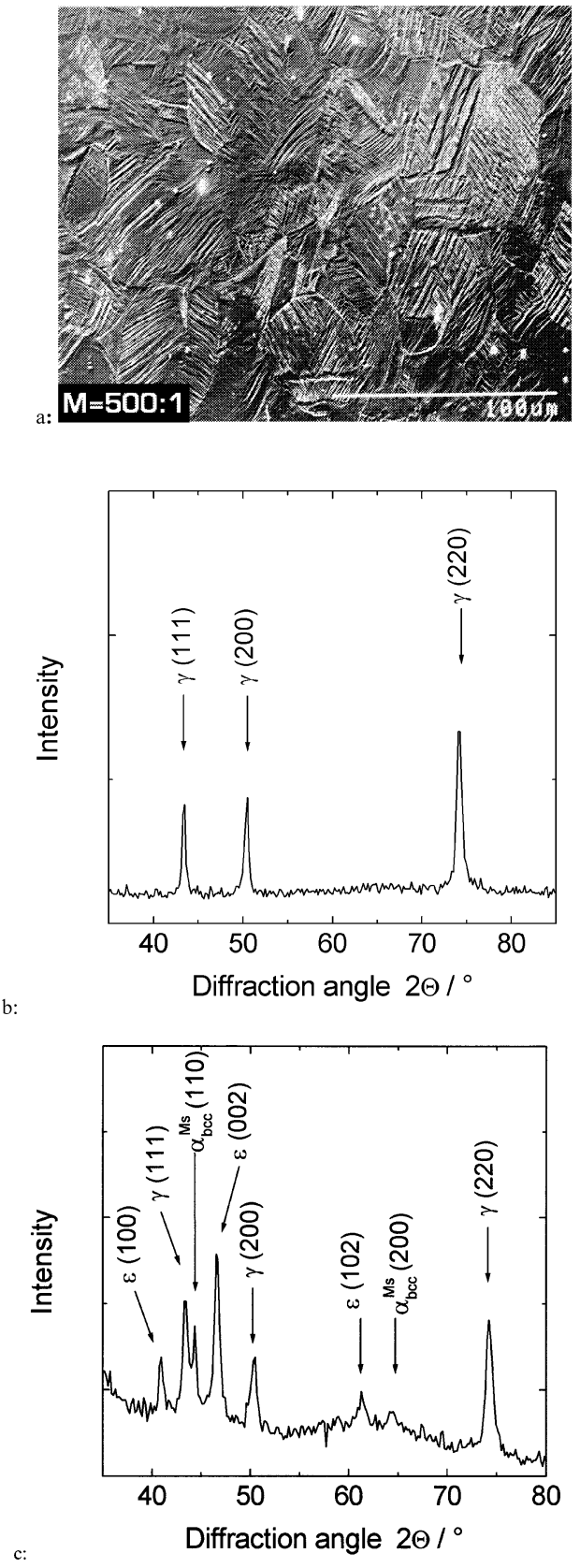

Fig. 12. SEM-micrograph (a) and X-ray diffraction patterns (b, c) of a highly deformed tensile sample of the $\mathrm{Fe}-25 \mathrm{Mn}-$ $\mathrm{Al}-3 \mathrm{Si}$ mass $\%$ TWIP steel; test temperature: $50^{\circ} \mathrm{C}$ (b) and $-100^{\circ} \mathrm{C}(\mathrm{c})$, total elongations: $\approx 75 \%$.

sitic phase transformation was detected by X-ray diffraction even at the maximum strain rate. The extremely high elongation is due to extensive mechanical twin formationTWIP_effect, see e.g. Fig. 12(a).

Important properties which are characterizing the impact behavior of deep drawing steels for automotive bodies and frame structures are the temperature dependent charpy impact toughness and the specific energy absorption $E_{\text {spec}}$, defined as deformation energy per unit volume at a given temperature $\left(25^{\circ} \mathrm{C}\right)$ and at strain rates of the order of $10^{2}$ to $10^{3} \mathrm{~s}^{-1}$, determined in flywheel and Hopkinson bar tests. $^{4,5,18)}$

The bar diagram of Fig. 14(a) represents the specific energy absorption $E_{\text {spec }}$ of the TWIP steel in comparison with selected conventional deep drawing steels, such as IF-steels 


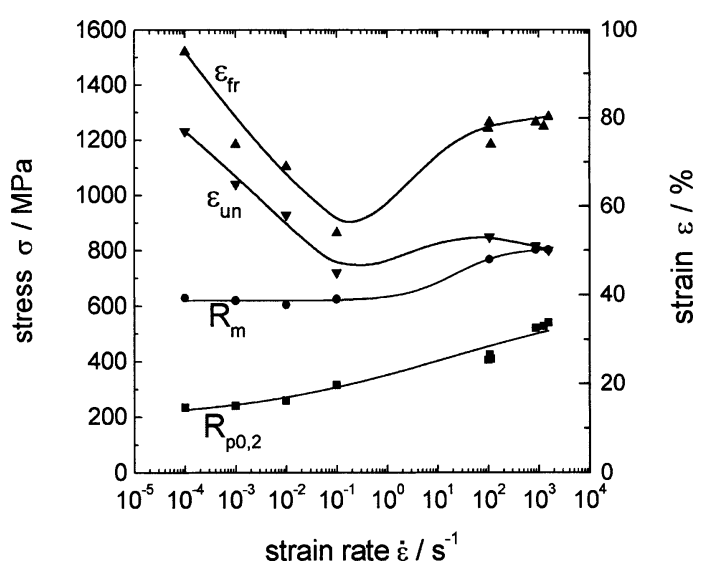

Fig. 13. $\mathrm{Fe}-25 \mathrm{Mn}-3 \mathrm{Al}-3 \mathrm{Si}$ mass $\%$ TWIP-steel: Yield stress $R_{\mathrm{p} 0.2}$, tensile strength $R_{\mathrm{m}}$, uniform elongation $\varepsilon_{\mathrm{un}}$ and total elongation $\varepsilon_{\mathrm{f}}$ as functions of strain rate.

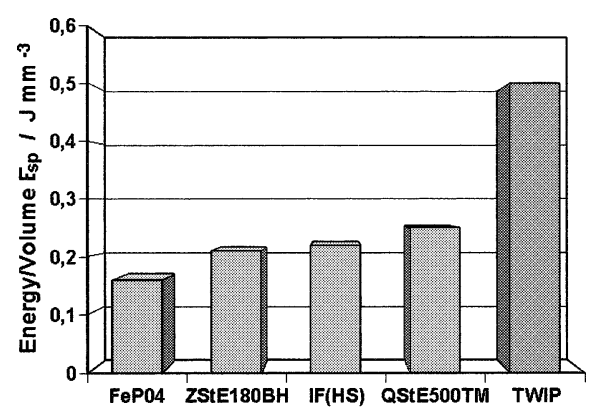

Fig. 14a. Specific energy absorption $E_{\text {spec, }}$ values of conventional deep drawing steels in comparison with the $\mathrm{Fe}-25 \mathrm{Mn}-$ 3Al-3Si mass $\%$ TWIP steel; test temperature: $20^{\circ} \mathrm{C}$, strain rate: $10^{2} \mathrm{~s}^{-1}$.

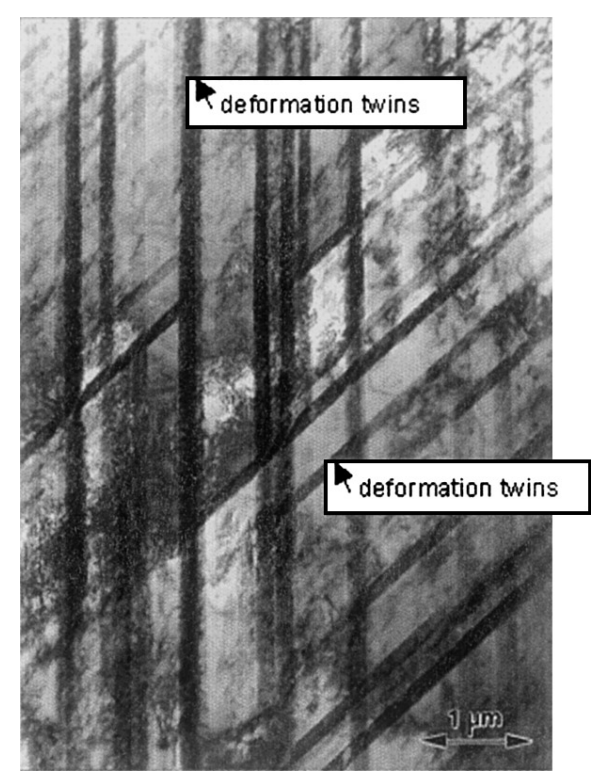

Fig. 14b. Fe-25Mn-3Al-3Si mass\% TWIP-steel: TEM bright field micrograph illustrating deformation twins on two intersecting $\{111\}$ planes in the austenite of the deformed tensile sample; plastic strain: $3 \%$, strain rate: $10^{3} \mathrm{~s}^{-1}$, test temperature: $25^{\circ} \mathrm{C}$.

(FeP04), bake hardening steels (Z St E $180 \mathrm{BH}$ ) and thermomechanically processed steels (Q St E $500 \mathrm{TM}$ ), respectively (Table 2) ${ }^{19,20)}$ It is shown in the diagram that the specific energy absorption value of the TWIP steel is about
Table 2. Chemical composition and tensile strength $R_{\mathrm{m}}$ of some selected conventional deep drawing steels in comparison.

\begin{tabular}{l|r|r|r|r|r|r}
\hline & $\begin{array}{r}\mathrm{C} \\
\text { [mass\%] }\end{array}$ & $\begin{array}{r}\mathrm{Si} \\
\text { [mass\%] }\end{array}$ & $\begin{array}{r}\mathrm{Mn} \\
\text { [mass\%] }\end{array}$ & $\begin{array}{r}\mathrm{P} \\
\text { [mass\%] }\end{array}$ & $\begin{array}{r}\mathrm{S} \\
\text { [mass\%] }\end{array}$ & $\mathrm{R}_{\mathrm{m}}$ [MPa] \\
\hline $\begin{array}{l}\text { FePO4 } \\
\text { IF - steel }\end{array}$ & $\leq 0.08$ & - & $\leq 0.4$ & $\leq 0.03$ & $\leq 0.03$ & $\leq 210$ \\
\hline $\begin{array}{l}\text { ZstE180BH } \\
\text { bake hardening steel }\end{array}$ & $\leq 0.04$ & $\leq 0.5$ & $\leq 0.7$ & $\leq 0.06$ & $\leq 0.03$ & $180-240$ \\
\hline $\begin{array}{l}\text { QstE500TM } \\
\begin{array}{l}\text { Thermomechanically } \\
\text { treated carbon steel }\end{array}\end{array}$ & $\leq 0.21$ & $0.1-0.6$ & $1-1.7$ & 0.035 & $\leq 0.03$ & 500 \\
\hline
\end{tabular}

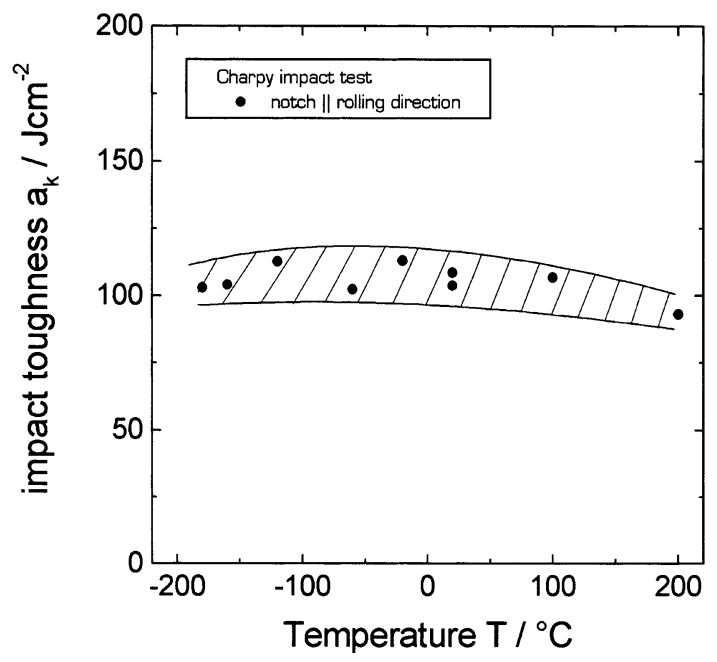

Fig. 15. Charpy impact toughness of the $\mathrm{Fe}-25 \mathrm{Mn}-3 \mathrm{Al}-3 \mathrm{Si}$ mass \% TWIP steel as a function of temperature. CharpyV-notch parallel to the rolling direction.

$0.5 \mathrm{~J} / \mathrm{mm}^{3}$ and the conventional deep drawing steel qualities possess energy absorption values between $0.16 \leq E_{\mathrm{spec}} \leq$ $0.25 \mathrm{~J} / \mathrm{mm}^{3}$, which are half of that of the very crash resistant supra-ductile TWIP steel or even less. The high-energy absorption is achieved due to extensive twin formation under high strain rate condition, as illustrated in the TEM bright field micrograph of Fig. 14(b).

The impact behavior as a function of the temperature was evaluated by performing impact tests in the temperature regime between -180 and $200^{\circ} \mathrm{C}$ using charpy V-notched test bars with reduced dimensions taken from as hot rolled sheets. The samples were half the size of the standardized test bars.

Figure 15 illustrates the impact energy as a function of the test temperature. Because of the two acting mechanisms: preferential twin formation in the temperature range from -70 to $200^{\circ} \mathrm{C}$ and the transition to partial martensitic $\gamma \rightarrow \varepsilon_{\mathrm{hcp}}^{\mathrm{Ms}} \rightarrow \alpha_{\mathrm{bcc}}^{\mathrm{Ms}}$ transformation below $-70^{\circ} \mathrm{C}$ no brittle fracture transition temperature was detected. This fact indicates clearly that the TWIP steel shows enhanced impact toughness and is not sensitive to embrittlement even at very low temperatures and high deformation rates. ${ }^{21)}$

\section{Summary}

A new class of innovative high-manganese TRIP and TWIP steels with superior mechanical properties was developed with special regard to high impact and crash resis- 
tance.

(1) The alloy design of these steels relies on defined stacking fault energies and austenite stability depending upon the additions of aluminum and silicon in medium concentrations.

(2) The metastable austenitic TRIP steel of the basic composition $\mathrm{Fe}-15 \mathrm{Mn}-3 \mathrm{Al}-3 \mathrm{Si}$ mass\%, with certain volume fractions of $\alpha$-ferrite and $\varepsilon$-martensite, exhibits high strength $(1100 \mathrm{MPa})$, an extraordinary strain hardening behavior $\left(d_{\sigma_{\text {true }}} / d_{\varphi_{\text {true }}}>4000\right)$, and enhanced tensile ductility $(55 \%)$ via multiple martensitic $\gamma \rightarrow \varepsilon_{\mathrm{hcp}}^{\mathrm{Ms}} \rightarrow \alpha_{\mathrm{bcc}}^{\mathrm{Ms}}$ transformations at ambient temperatures.

(3) The austenitic TWIP steel of the composition $\mathrm{Fe}-$ $25 \mathrm{Mn}-3 \mathrm{Al}-3 \mathrm{Si}$ mass $\%$ shows supraductility, moderate flow stresses $(280 \mathrm{MPa})$ and higher tensile strength $(650 \mathrm{MPa})$ in a wide strain rate range at room and somewhat lower temperatures. The extremely high elongations (80-95\%) achieved at lower strain rates $\left(<10^{-3} \mathrm{~s}^{-1}\right)$ and at ultrahigh strain rates $\left(>10^{2} \mathrm{~s}^{-1}\right)$ are due to extensive twin formation.

(4) The deep drawing and stretch forming behavior of the TRIP steel is significantly improved by increasing the deformation rate to $10^{-1} \mathrm{~s}^{-1}$. This promotes multiple martensitic transformations, which leads to enhanced plasticity. The forming limit of sheet samples of the TWIP steel exceeds that of austenitic stainless steels.

(5) The high specific energy absorption $\left(0.5 \mathrm{~J} / \mathrm{mm}^{3}\right)$ and the prominent impact toughness even at extremely high strain rates and low temperatures without brittle-ductile transition are promoting potential applications of these steels in the automotive industry, in civil engineering, and in the cryogenic technique.

\section{REFERENCES}

1) K. Ishida and T. Nishizawa: Trans. Jpn. Inst. Met., 15 (1974), 225.

2) B. Sundman, B. Jansen and L.-O. Andersen: Calphad, 9 (1985), 153.

3) O. Grässel, G. Frommeyer, C. Derder and H. Hofmann: J. Phys. France, 7 (1997), C5-383.

4) N.-Nasser, Y. F. Li and B. Isaacs: Mech. Mater, 17 (1994), 111.

5) L. W. Meyer, E. Staskewitch and A. Burbkes: Mech. Mater, 17 (1994), 203.

6) J. Kühne: Wiss. Z. Tech. Hochsch. Magdeburg, 24 (1980), Heft 1.

7) A. Sato, K. Soma and T. Mori: Acta Metall., 30 (1982), 1901.

8) S. S. Hecker, M. G. Stout, K. P. Staudhammer and J. L. Smith: Metall. Trans., 13A (1982), 619.

9) Y. Tomota, M. Strum and J. W. Morris, Jr.: Metall. Trans. A, 17A (1986), 537.

10) Y. Tomita, and T. Iwamoto: Int. J. Mech. Sci., 12 (1995), 1295.

11) O. Grässel and G. Frommeyer: Mater. Sci. Technol., 14 (1998) 1213.

12) H. Schumann: Arch. Eisenhüttenwes., 38 (1967), 647.

13) P. H. Kelly: Acta Metall., 13 (1965), 635.

14) Y. G. Kim, Y. S. Park and J. K. Han: Metall. Trans. A, 16A (1985), 1689.

15) S. H. Hong and Y. S. Han: Scr. Metall. Mater., 32 (1995), No. 9, 1489.

16) Y. G. Kim, J. M. Han and J. S. Lee: Mater. Sci. Eng. A, A114 (1989), 51.

17) U. Brüx, G. Frommeyer, O. Grässel, L.W. Meyer, L. Krüger and A. Weise: Steel Res., 73 (2002), No 6+7, 294.

18) K. Sato, M. Ichinose, Y. Hirotsu and Y. Inoue: ISIJ Int., 29 (1989), No.10, 868 .

19) O. Grässel, L. Kruger, G. Frommeyer and L.W. Meyer: Int. J. Plast., 16 (2000) 1391.

20) K. Miura, S. Tagaki, T. Hira, O. Furukimi and S. Tanimura: High Strain Rate Deformation of High Strength Sheet Steels for Automotive Parts, Society of Automotive Engineers, Inc. Warrendale, PA, (1998).

21) B. W. Oh, S. J. Cho, S. H. Hong, Y .G. Kim,W. J. Kim and Y. P. Kim: Adv. Cryogenic Eng., 40 (1994), 1183. 